\title{
Learning from an Incident Reporting System: Developing a Strategy to Prevent Medication Errors Among Nursing Students
}

\author{
Shwu-Fen CHIOU, RN, $\mathrm{PhD}^{\mathrm{a}, 1}$ and Kuei-Fen LIU, RN, PhD \\ ${ }^{a}$ School of Nursing, National Taipei University of \\ Nursing and Health Sciences, Taiwan, ROC
}

\begin{abstract}
Medication errors occur during clinical learning for nursing students. This study aimed to develop learning cases to prevent medication errors using analysis of data from an incident reporting system. This study utilized an action research approach to develop learning cases. These learning cases were implemented with problem-based learning (PBL) method and self-learning materials strategies. The results showed that repeated occurrences of medication errors and near misses were reduced after implementing the new teaching strategy.
\end{abstract}

Keywords. Incident reporting system, medication error, nursing education

\section{Introduction}

Nursing students are often confronted with unexpected incident events during the clinical learning process. Medication errors are the most frequent accidents. A systematic review indicated that $28.3 \%-32.1 \%$ of nursing students experienced medication errors. About $54.4 \%$ of nursing students experienced near misses in medication administration. [1] Wolf et al. used the National Coordinating Council for Medication Error Reporting and Prevention (NCC MERP) Index to analyze the levels of medication errors in the reporting data, and found that $3.83 \%$ of the events were category B (An error occurred but the error did not reach the patient), and $70.57 \%$ were category $C$ (An error occurred that reached the patient but did not cause patient harm). [2]

Our school established an incident reporting system in 2006. The reporting of incident events includes medication errors, needlestick injuries, and other events. Medication errors events accounted for about $70 \%$ of all events, and $45.82 \%$ of the events were category B. Approximately $36.36 \%$ of students repeated category B medication errors in different practicum courses. Therefore, this study aimed to analyze the causes and patterns of medication errors events based on the incident reporting system, and to develop teaching strategies. An additional aim was to evaluate the effectiveness of the new teaching strategy.

\footnotetext{
${ }^{1}$ Corresponding Author, Shwu-Fen Chiou, School of Nursing, National Taipei University of Nursing and Health Sciences, No. 365, Ming-Te Road, Peitou District, Taipei City 11219, Taiwan, ROC; E-mail: schwufen@ntunhs.edu.tw.
} 


\section{Methods}

This study applied an action research approach by Mertler (2017). [3] The research design was divided into the following stages. Planning stage: First, we analyzed the reporting system data to determine categories of medication events, as well as the pattern of causes. Then, we developed learning cases for medication error prevention as source materials for PBL strategy that included three scenes.

Acting stage: Thirty-one nursing students whose first medication error occurred during nursing practicum course were recruited to this study. Thirteen students whose first medication error occurred during "Basic nursing practicum" were assigned to PBL group (taught by faculty in PBL principle). Another eighteen students in the same academic year were assigned to the control group (taught by traditional teaching method). Participants in the PBL group improved drug calculation from 3.56 to 6.56 points (out of 8 points), and medication knowledge increased from 7 to 9.67 points (out of 10 points). There were statistically significant differences in both drug calculation and medication knowledge used Wilcoxon signed rank test for the PBL group. The z-value of drug calculation was $-2.106(\mathrm{p}=.035)$ and medication knowledge was $-2.546(\mathrm{p}=.011)$. In the following semester, the rate of repeated occurrences of medication errors in the PBL group students was approximately $23.08 \%$, and control group students $33.33 \%$; with a $10 \%$ difference.

Students in PBL group indicated that PBL discussions were rewarding. However, they reflected that they were labeled as students who needed special attentions from their clinical instructors. Nursing faculty also indicated that the PBL discussions were timeconsuming. Therefore, in developing stage, we produced an MPEG Audio Layer 3 (MP3) self-learning video recordings from the same learning cases. We provided MP3 self-learning cases to students through clinical instructors. The students reviewed these recorded learning cases before they started their "Medical-Surgical Nursing Practicum II" course.

\section{Results}

A total of 74 category B medication error events occurred among all students within the three years (from 2012 to 2014) prior to the implementation of the MP3 self-learning case. After the MP3 self-learning case were implemented (from 2015 to 2017), a total of 53 category B medication error events occurred. The category B medication error reduced twenty-one events after the MP3 self-learning cases implementation of three years, with an average reduction of category B medication error was approximately seven events per year.

\section{Conclusions}

This study analyzed data from an incident reporting system, developed learning cases regarding the prevention of medication errors, and provided various teaching strategies to students that experienced medication errors. Although the reporting system information was limited by the students' willingness to self-report. [4] However, this study showed the incident reporting system can serve as an important empirical source to identify medication error patterns and develop strategies to prevent medication errors. 
Simultaneously, this study indicated that MP3 self-learning cases were effective in preventing near misses of medication errors.

\section{References}

[1] Asensi-Vicente J, Jimenez-Ruiz I, Vizcaya-Moreno MF. Medication errors involving nursing students: A systematic review. Nurse Educator 43 (2018), E1-E5.

[2] Wolf ZR, Hicks R, Serembus JF. Characteristics of medication errors made by students during the administration phase: a descriptive study. Journal of Professional Nursing 22 (2006), 39-51.

[3] Mertler CA. Action research: Improving schools and empowering educators. Sage Publications, 2017.

[4] Chan R, Booth R, Strudwick G, Sinclair B. Nursing students' perceived self-efficacy and the generation of medication errors with the use of an electronic medication administration record (eMAR) in clinical simulation. International Journal of Nursing Education Scholarship 16 (2019). 